\title{
The Economic Cost of COVID Lockdowns: An Out-of-Equilibrium Analysis
}

\author{
Antoine Mandel $^{1} \cdot$ Vipin Veetil ${ }^{2}$
}

Received: 7 May 2020 / Accepted: 6 June 2020 / Published online: 19 June 2020

(C) Springer Nature Switzerland AG 2020

\begin{abstract}
This paper estimates the cost of the lockdown of some sectors of the world economy in the wake of COVID-19. We develop a multi sector disequilibrium model with buyer-seller relations between agents located in different countries. The production network model allows us to study not only the direct cost of the lockdown but also indirect costs which emerge from the reductions in the availability of intermediate inputs. Agents determine the quantity of output and the proportions in which to combine inputs using prices that emerge from local interactions. The model is calibrated to the world economy using input-output data on 56 industries in 44 countries including all major economies. Within our model, the lockdowns are implemented as partial reductions in the output of some sectors using data on sectoral decomposition of capacity reductions. We use computational experiments to replicate the temporal sequence of the lockdowns implemented in different countries. World output falls by $7 \%$ at the early stage of the crisis when only China is under lockdown and by $23 \%$ at the peak of the crisis when many countries are under a lockdown. These direct impacts are amplified as the shock propagates through the world economy because of the buyer-seller relations. Supply-chain spillovers are capable of amplifying the direct impact by more than two folds. Naturally, the substitutability between intermediate inputs is a major determinant of the amplification. We also study the process of economic recovery following the end of the lockdowns. Price flexibility and minor technological adaptations help in reducing the
\end{abstract}

This article is part of the Topical Collection on Economics of COVID-19

Mandel acknowledges support from the H2020 framework programme via grant 884565 - TIPPING.plus

Mandel acknowledges the support by the Project ExSIDE. This work has received funding from the European Union's Horizon 2020 research and innovation programme under the Marie $36 \mathrm{Sk}$ lodowska-Curie grant agreement No 721846, "Expectations and Social Influence Dynamics in Economics (ExSIDE)".

Antoine Mandel

antoine.mandel@univ-paris1.fr

Vipin Veetil

vipin@iitm.ac.in

1 Paris School of Economics, Université Panthéon-Sorbonne, Paris, France and

Climate Finance Alpha, Paris, France

2 Indian Instiute of Technology Madras, Chennai, India 
time it takes for the economy to recover. The world economy takes about one quarter to move towards the new equilibrium in the optimistic and unlikely scenario of the end of all lockdowns. Recovery time is likely to be significantly greater if partial lockdowns persist.

Keywords COVID-19 · Lockdown · Production network · Multi market model · Disequilibrium dynamics

\section{Introduction}

In February-March 2020 the world economy entered uncharted territory. Never before has an economy as interlinked as the present system been subject to shocks as large as the lockdowns in the wake of COVID-19. Already in March with the lockdown of China alone, Indian pharmaceutical companies began to struggle as they procure more than $70 \%$ of active pharmaceutical ingredients from sellers located within the geographical boundries of China (Chatterjee 2020). Matters are not very different in the US and other parts of the world. In a recent survey conducted by the US based Institute for Supply Management, nearly three quarters of the respondents said they had experienced supply chain disruptions (Zeiger 2020). Similarly, Hassan et al. (2020) in a study of the earning calls of more than 12,000 publicly listed companies based in more than 70 countries find that supply chain disruption has become one of the primary concerns of firms around the world. Interestingly enough the stock markets have responded more to COVID-19 than to the Spanish Flu which killed rough $2 \%$ of the world population (Barro et al. 2020). Baker et al. (2020), among others, have argued that the sizeably greater response of stock markets to COVID-19 may have something to do with the greater interlinkage of the global economy coupled with the supply-chain disruption caused by the lockdowns. In this paper, we use an agent-based model of out-of-equilibrium economic dynamics to analyze the propagation of the lockdown shocks through input-output linkages. And on this basis assess the short-term costs of the COVID lockdowns.

Our model builds on Gualdi and Mandel's (2016) agent-based extension of Acemoglu et al.'s (2012) equilibrium production network model. We study the out-of-equilibrium dynamics of the system by unbundling a sequence of decisions which are assumed to occur contemporaneously in equilibrium models. This out-of-equilibrium approach allows us to characterise relative price deviations, spill over of excess demands from one market to another, and non-linear paths of sectoral and aggregate recovery after an exogenous shock. Note that within such a general disequilibrium setting, prices at each time step are not generated by a Walrasian auctioneer who considers the inter-relations between all markets. Rather prices emerge from the interactions between agents who act as buyers in their input market and sellers in their output market. These decentralized interactions mean that the system can be out-of-equilibrium for a substantial period of time. Furthermore, the spill over of excess demands from one market to another is a major source of the disruption of the economic system and therefore an important determinant of the cost the lockdown. Within our setting, the propagation of the lockdown shock through the system generates miscoordination as firms no longer combine inputs in proportions determined by equilibrium prices. The economy suffers not only from the shortage of intermediate inputs but also because inputs are not combined in equilibrium proportions. This is not because firms do not minimise costs, they do, but because firms face disequilibrium prices using which they minimize costs. The propagation of disequilibrium prices and the miscoordination it generates are an important 
determinant of the cost of the lockdown. It is likely therefore that equilibrium models which ignore such dynamics understate the cost of the supply-chain disruptions.

We calibrate our model to the world economy using the World Input-Output Table with 56 sectors in 44 countries (Timmer et al. 2015). We initialise the world economy by setting all variables to their equilibrium values corresponding to the primitives defined by the input-output relations, the exponents of the production functions, and other parameters. We then shock the equilibrated system with the temporal sequence of the lockdowns observed in the real world using publicly available information on the start and end dates of the lockdown. We therefore have two distinct lockdown periods. The first of which extends from February 1 to March 15 and the second of which begins on 15 March. Most world economies enforced a lockdown within the first 10 days of the second period, with the lockdown duration ranging from 40 to 60 days. Note that the lockdown policies were not homogeneous in their sectoral composition. Many countries distinguished between essential and non-essential services, allowing some sectors to operate at reduced capacity, while others were completely shutdown. We shock the equilibrium world economy using a sectoral decomposition of lockdown provide by the IFO-Institute (2020). We then study the geographical and sectoral propagation of the lockdown shocks using computational experiments on our calibrated model economy. We compute not only the direct cost of the lockdown but also the indirect costs which emerge from supply-chain disruptions. Our estimates suggest that the indirect costs can be roughly equivalent to the direct costs, with the relation between two being mediated by the degree of substitutability between intermediate inputs. An economy with high complementarity between intermediate inputs will suffer more from supply-chain disruptions than an economy with high substitutability.

The role of price flexibility is limited because the major hurdle faced by firms is sizeable reductions in the availablity of inputs, with few input producers being in a position to respond to the price changes by producing more. Our estimates suggest that the lockdown reduces global output by about $33 \%$ at the peak of the lockdown, with the yearly impact being more than $9 \%$ of annual GDP.

The remaining of the paper is organized as follows. Section "Related Literature" reviews the related literature. Section "The Model" introduces the model. Section "Shock Propagation in the Global Economy" presents the results of our analysis of the COVID lockdowns. Section "Concluding Remarks" concludes the paper.

\section{Related Literature}

\section{The Literature On The Economics of COVID}

The sheer size of market responses to the pandemic itself and the lockdowns in its wake has motivated a growing literature on the economic impact of the lockdowns (Gormsen and Koijen 2020; Alfaro et al. 2020). The models used in the literature can be divide into three classes. The first class of models study the direct impact of COVID and related lockdowns, but ignore indirect effects that emanate from supply-chain relations. The second class of models study the direct and indirect impact within an equilibrium framework. They do not consider temporary relative prices effects and overshooting of some sectors in the disequilibrium dynamics that are likely to follow the lockdown. The third class of models study the direct and indirect effect within a framework general enough to incorporate disequilibrium dynamics. Each class of models can be further subdivided into those calibrated to national 
economies and those which consider world input-output relations. They can also be subdivided based on whether they are solely economic models or economic models embedded within an epidemiological model. Needless to say, not all models fit neatly into one of the three classes.

Several economists have developed models that fall roughly within the first class. They are not high dimensional in terms of the sectors they consider but attempt to present a rough but useful estimate of the direct cost of the lockdown. Bodenstein et al. (2020), for instance, combine an epidemiological model with a two sector model of the US economy. Similarly, Toda (2020) combines an SIR model with a standard asset pricing model to predict the decline in stock prices. Bayer et al. (2020) use a model with a handful of different kinds of firms to study the multiplier associated with the fiscal spending by various governments in response to the COVID slowdown. Fornaro and Wolf (2020) study the effectiveness of macroeconomic policy using a New Keynesian model which represents the global economy as a single production unit. And del Rio-Chanona et al. (2020) study the direct impact of the lockdowns without analysing supply-chain disruptions.

The second class of models, i.e. those that study indirect network effects, have fewer inhabitants than the first. Walmsley et al. (2020) use a computable general equilibrium model to estimate the cost of the lockdowns for the US economy. They consider the supply chain within the US but ignore international buyer-seller relations. The World Bank (2020) too uses a computable general equilibrium model to study the impact on Africa. Barrot et al. (2020) study the fall in GDP because of social distancing policies by considering direct and indirect impacts. They calibrate their model to granular data on France and more coarse data on Europe. These equilibrium production network models are closely related to recent work on the role of buyer-seller linkages in amplifying supply shocks (Carvalho et al. 2014; Barrot and Sauvagnat 2016; Boehm et al. 2019).

And then there are a handful of models which fall between the second and the third class. Inoue and Todo (2020) presents one such model. They extend and calibrate Hallegatte's (2008) input-output model to study the impact of the shutdown of Tokyo on the Japanese economy. Inoue and Todo's (2020) simulations suggest that though Tokyo accounts for roughly one fifth of the national output, its lockdown would generate a four fifths reduction in Japanese output. Inoue and Todo's (2020) approach is similar to that of the Asian Development Bank (2020), which studied the supply-chain impact of COVID lockdowns using their Multi Regional Input-Output Table (MIROT) model. These models do not assume equilibrium but neither do they explicitly characterise the out-of-equilibrium dynamics which emerge from inter-related microeconomic decisions in response to exogenous shocks.

\section{Out-of-Equilibrium Equilibrium Models}

From a theoretical and technical point of view our paper is closely related to older work on disequilibrium multi market models which study the dynamic properties of input-output systems (Jorgenson 1961). Barro and Grossman's (1971) pioneering paper on general disequilibrium sparked a whole literature on understanding the dynamic properties of adjustments within a network economy. Some of these contributions are worth mentioning in the light of their significance in analyzing COVID dynamics. Benassy (1975) developed a model with decentralized trades in a money using economy with arbitrary many markets. He intended to develop something comparable to the Arrow-Debreu system in its generality. Green and Laffont (1980) developed a model of disequilibrium inventory dynamics with a single storable output, money, and labor. Other important contributions include those by Rosen and Nadiri (1974), Sharp and Perkins (1977), and Muellbauer and Portes (1978). 
These contributions study how excess demand spills over from market to another. Overall, this literature generalized Leontief's (1941) classic treatment of the structure of the American economy. Our model in essence is yet another step towards realizing the goal of developing a general disequilibrium model which in its treatment of prices, quantities, input combinations, and ultimately the network structure itself is able to complement equilibrium analysis on an equal footing.

Our contribution also related to recent work that uses agent-based models to analyze economic dynamics out-of-equilibrium. Numerous economists have used agent-based models to investigated the propagation of shocks in stylized models of the economic system (Gatti et al. 2005; Weisbuch and Battiston 2007; Battiston et al. 2007). Economists before us have also developed empirically grounded agent-based models to analyse middle to long term impacts of policy on economic growth (Dosi et al. 2013; Dawid et al. 2014). And more recently, agent-based models have been used to analyze potential economic impacts of climate change (Lamperti et al. 2019). Our paper adds to this literature by providing an agent-based analysis of the short-term impact of economic shocks in a fully calibrated model at a higher level of granularity.

Ultimately, the question of equilibrium versus disequilibrium models must be settled empirically. In so far as the economic system is sufficiently close to equilibrium, there are good reasons to use equilibrium models not the least of which is their analytical tractability, and the consistency between micro decisions and macro states. In certain circumstances however the economy may be far from equilibrium at least for short periods of time, in which case general disequilibrium models are more suitable. Symptomatic evidence suggests the world economy has been jolted away from equilibrium by the COVID lockdown shocks. Financial markets have exhibited aberrant and volatile behaviour with the VIX index close to historic highs (Gormsen and Koijen 2020). And reported unemployment in the US and Europe have witnessed an unprecedented jump (Bernstein et al. 2020). These indicators suggest we are not in normal times. While there are no econometric studies yet to sort between equilibrium and disequilibrium models of the COVID lockdown, an older generation of econometric studies suggest several parts of an economy can remain out-of-equilibrium for more than a quarter in response to exogenous shocks (Boschen and Grossman 1982; Rudebusch 1989), including credit markets (Takatoshi and Ueda 1981), labor markets (Rosen and Quandt 1978), housing markets (Fair and Jaffee 1972; Riddel 2004), and the market for industrial output (Seiichi et al. 1982). None of this is to suggest that it is trivial to econometrically distinguish between equilibrium and disequilibrium states (Quandt 1978; Ito 1980; Gourieroux and Monfort 1980), but that there are sufficiently good reasons to attempt to do so.

\section{The Model}

\section{General Equilibrium Framework}

We represent the world economy as a network of input-output relationships embedded in a general equilibrium model as in Acemoglu et al. (2012). The economy consists of $K$ countries, each comprising of the same $L$ industries. The model is calibrated to the world economy using the world input-output database (Timmer et al. 2015), which provides inputoutput relationships between $L=56$ industries in $K=44$ countries. The data set includes all major economies and a composite country representing the rest of the world. Within our model, each industry of each country is represented as one monopolistically competitive 
firm. Each of the $K$ countries also has two representative households, which are differentiated by the source of their revenues. The workers' representative household receives the labor share of value-added from each domestic sector, while the capitalists' receives the capital share.

Remark 1 We index each country's worker by 1 , capitalist by 2 , and firms by $\{3, \cdots, L+2\}$. There are thus $M=L+2$ agents in each country and we refer to the $i^{t h}$ agent in country $k$ either as $(i, k)$ or as $(K-1)(L+2)+i$ (so that agents in country $k$ are indexed by $\{(k-1)(L+2), \cdots k(L+2)\})$. Conversely, we let $k(j)$ denote the country of agent $j$, with $w(j)$ and $c(j)$ denoting the worker and capitalist of country $j$. Finally, we let $M=$ $2 K$ denote the number of agents, $\mathcal{M}$ the set of agents, $\mathcal{F}$ the set of firms, $\mathcal{H}$ the set of households, and $\mathcal{K}$ the set of countries.

Each firm $j$ produces a differentiated good using capital provided by the domestic capitalist, labor provided by the domestic worker, and a combination of domestic and international inputs. There are thus a total of $M$ goods in the model corresponding to the output of each industry, differentiated by country as well as by the labor and capital services used in each country.

The production possibilities of each firm is described by a production function combining domestic labor and capital services with the domestic and international inputs put together using a CES form. Namely, the production technology of firm $j$ is of the form:

$$
f_{j}\left(x_{w(j)}, x_{c(j)},\left(x_{h}\right)_{h \in \mathcal{F}}\right)=x_{w(j)}^{\alpha_{w, j}} x_{c(j)}^{\alpha_{c, j}}\left(\sum_{h \in \mathcal{F}} \beta_{h, j} x_{h}^{\theta}\right)^{\frac{\left(1-\alpha_{c}-\alpha_{k}\right)}{\theta}}
$$

where $x_{w(j)}$ and $x_{c(j)}$ are the domestic labor and capital inputs, $\alpha_{w, j}$ and $\alpha_{c, j}$ are the (nominal) share of labor and capital in the input mix. The elasticity of substitution between inputs is given by $\frac{1}{(1-\theta)}$. Worker $i$ provides a fixed amount of work $e_{i} \in \mathbb{R}_{+}$and capitalist $i$ provides a fixed amount of capital services $e_{i^{\prime}} \in \mathbb{R}_{+}$every period. All households have CES preferences of the form:

$$
u_{i}\left(\left(x_{h}\right)_{h \in \mathcal{F}}\right)=\left(\sum_{h \in \mathcal{F}} \beta_{h, i} x_{h}^{\theta}\right)^{\frac{\left(1-\alpha_{\mathcal{C}}-\alpha_{k}\right)}{\theta}}
$$

Remark 2 The functional form introduced in Eq. 1 provides an extremely stylised description of the substitutability between inputs. In particular, it does not distinguish the substitutability between inputs from different industries and substitutability between inputs of the same industry from different countries. This simplifying assumption must be assessed in view of the intended usage of the model: inputs will be actually substituted only in the interim period following a shock. Moreover, the ridigity of the assumption is somewhat tempered by the fact that we consider inputs that correspond to sectoral aggregates.

We denote the economic system introduced above as $\mathcal{E}(\mathcal{M}, \alpha, \beta, w, c)$. In this setting, a general equilibrium is usually defined as follows.

Definition 1 A general equilibrium of the economy $\mathcal{E}(\mathcal{M}, \alpha, \beta, \theta)$ is a collection of prices $p^{*} \in \mathbb{R}_{+}^{M}$, production levels $y^{*} \in \mathbb{R}_{+}^{M}$ and commodity flows $\left(x_{i, j}^{*}\right)_{i, j \in \mathcal{M}} \in \mathbb{R}_{+}^{M \times M}$ such that: 
1. Consumers maximize their utility under their budget constraint. That is, for all $i \in \mathcal{H}$, $\left(y_{i}^{*},\left(x_{h, i}^{*}\right)_{h \in \mathcal{F}}\right)$ is a solution to:

$$
\left\{\begin{array}{c}
\max u_{i}\left(\left(x_{h, i}\right)_{h \in \mathcal{F}}\right) \\
\text { s.t. } \sum_{h \in \mathcal{F}} p_{h}^{*} x_{h, i}^{*} \leq p_{i}^{*} y_{i}^{*}
\end{array}\right.
$$

2. Firms maximize profits. That is, for all $j \in \mathcal{F},\left(y_{j}^{*},\left(x_{h, j}^{*}\right)_{h \in \mathcal{F}}\right)$ is a solution to:

$$
\left\{\begin{array}{c}
\max p_{j}^{*} y_{j}-\sum_{h \in \mathcal{M}} p_{h}^{*} x_{h, j} \\
\text { s.t. } f_{j}\left(x_{w(j), j}^{*}, x_{c(j), j}^{*},\left(x_{h, j}^{*}\right)_{h \in \mathcal{F}}\right) \geq y_{j}^{*}
\end{array}\right.
$$

3. Markets clear. That is, for all $i \in M$, one has:

$$
y_{i}^{*}=\sum_{j=1}^{M} x_{i, j}^{*} .
$$

where for all $i \in \mathcal{H}, y_{i}^{*}=e_{i}$ to account for the inelastic supply of labor and capital services.

Remark 3 Note that there are no profits to be distributed at equilibrium because production technologies exhibit constant returns. Namely, one has for all $j \in \mathcal{F}$ :

$$
p_{j}^{*} y_{j}^{*}=p^{*} \cdot x_{\cdot, j}^{*}
$$

The no profit condition implies that the income of households is completely determined by their supply of labor or capital services.

The general equilibrium of the economy defines nominal input-output flows between each pair of agents. These flows form the input-output network of the economy. The structure of this network can be captured by a column-stochastic matrix $A^{*}=\left(a_{i, j}^{*}\right)_{i, \in \mathcal{M}} \in$ $\mathbb{R}_{+}^{\mathcal{M} \times \mathcal{M}}$ whose coefficient $a_{i, j}^{*}$ captures the share of $j^{\prime}$ s equilibrium spending directed towards $i$, that is $a_{i, j}^{*}=\frac{p_{i}^{*} x_{i, j}^{*}}{p^{*} \cdot x_{\cdot, j}^{*}}$. In particular if $j \in \mathcal{F}$ and $i \in \mathcal{F}, a_{i, j}^{*}$ represents the amount of expenditure on intermediary inputs spent on good $i$ per unit of revenue of firm $j$ while for $i \in \mathcal{H}, a_{i, j}^{*}$ represents the added-value received by household $i$ per unit of revenue of firm $j$.

\section{Out-of-Equilibrium Dynamics}

Following Gualdi and Mandel (2016), we define out-of-equilibrium dynamics on the basis of decentralized agent-interactions.

We consider discrete periods of time indexed by $t \in \mathbb{N}$. Every period the state of each agent $i \in \mathcal{M}$ is determined by the following variables:

- Its stock of output $q_{i}^{t} \in \mathbb{R}_{+}$(equal to labor or capital supply for households).

- The price of its output $p_{i}^{t} \in \mathbb{R}_{+}$.

- Its monetary balances $m_{i}^{t}$. The monetary balances of the household correspond to its consumption budget. The monetary balances of the firm correspond to its working capital. 
- The share $a_{j, i}^{t} \in \mathbb{R}_{+}^{N}$ of the budget to be spend on input $j$.

These variables are updated according to the following sequence of actions and interactions:

1. Each agent $i \in \mathcal{M}$ receives the nominal demand $\sum_{j \in \mathcal{M}} \alpha_{i, j}^{t} m_{j}^{t}$.

2. Agents adjust their prices frictionally towards their market-clearing values according to:

$$
p_{i}^{t}=\tau_{p} \bar{p}_{i}^{t}+\left(1-\tau_{p}\right) p_{i}^{t-1}
$$

where $\tau_{p} \in[0,1]$ is a parameter measuring the speed of price adjustment and $\bar{p}_{i}^{t}$ is the market-clearing price defined as follows. Given the nominal demand $\sum_{j \in \mathcal{M}} a_{i, j}^{t} m_{j}^{t}$ and the output stock $q_{i}^{t}, \bar{p}_{i}^{t}$ the market clearing price for firm $i$ is:

$$
\bar{p}_{i}^{t}=\frac{\sum_{j \in \mathcal{M}} a_{i, j}^{t} m_{j}^{t}}{q_{i}^{t}}
$$

3. Whenever $\tau_{p}<1$, markets do not clear (except if the system is at a stationary equilibrium). In case of excess demand, we assume that buyers are rationed proportionally to their demand. In case of excess supply, we assume that the amount $\bar{q}_{i}^{t}:=$ $\min \left(q_{i}^{t}, \frac{\sum_{j \in \mathcal{M}} a_{i, j}^{t} m_{j}^{t}}{p_{i}^{t}}\right)$ is actually sold and rest of the output is stored as inventory. 1 These inventory dynamics together with production based on the purchased inputs yield the the following evolution of the output stock:

$$
q_{i}^{t+1}=q_{i}^{t}-\bar{q}_{i}^{t}+f_{i}\left(\frac{a_{w(i), i}^{t} m_{i}^{t}}{p_{w(i)}^{t}}, \frac{a_{c(i), i}^{t} m_{i}^{t}}{p_{c(i)}^{t}},\left(\frac{a_{j, i}^{t} m_{i}^{t}}{p_{j}^{t}}\right)_{j \in \mathcal{M}}\right)
$$

Note that when $\tau_{p}=1$, markets always clear (one has $\bar{q}_{i}^{t}=q_{i}^{t}$ ) and Eq. 5 reduces to

$$
q_{i}^{t+1}=f_{i}\left(\frac{a_{w(i), i}^{t} m_{i}^{t}}{p_{w(i)}^{t}}, \frac{a_{c(i), i}^{t} m_{i}^{t}}{p_{c(i)}^{t}},\left(\frac{a_{j, i}^{t} m_{i}^{t}}{p_{j}^{t}}\right)_{j \in \mathcal{M}}\right)
$$

4. Money balances are determined on the one hand by the purchase of inputs and the sales of output. More specifically:

$$
\forall i \in M, m_{i}^{t+1}=m_{i}^{t}+p_{i}^{t} \bar{q}_{i}^{t}-\sum_{j \in \mathcal{M}} a_{j, i}^{t} \frac{\bar{q}_{i}^{t}}{q_{i}^{t}} m_{i}^{t}
$$

Note that Eq. 7 can be interpreted as assuming that firms have myopic expectations about their nominal demand (i.e. firms assume they will face the same nominal demand next period) and target a balanced budget (net of labor and capital costs paid to households).

5. As for the evolution of input shares, agents frictionally adjust their input combinations towards the cost-minimizing value according to:

$$
a_{\cdot, i}^{t+1}=\tau_{w} \bar{a}_{\cdot, i}^{t}+\left(1-\tau_{w}\right) a_{\cdot, i}^{t}
$$

where $\tau_{w} \in[0,1]$ measures the speed of technological adjustment and $\bar{a}_{\cdot, i}^{t} \in \mathbb{R}^{M}$ denotes the optimal input weights for firm $i$ given prevailing prices. Those weights are defined as the solution to the following optimization problem:

\footnotetext{
${ }^{1}$ The household does not carry an inventory. Equation 5 is modified accordingly in this case.
} 


$$
\left\{\begin{array}{cc}
\max f_{i} & \left(\frac{a_{w(i), i}}{p_{w(i), i}^{t}}, \frac{a_{c(i), i}}{p_{c(i), i}^{t}}\left(\frac{a_{j, i}}{p_{j}^{t}}\right)_{j \in \mathcal{M}}\right. \\
\text { s.t. } & \sum_{j \in \mathcal{M}} a_{j, i}=1
\end{array}\right.
$$

The tâtonnement process (see e.g. Arrow and Hurwicz (1958)) aims to determine marketclearing conditions by adapting price dynamics to the optimizing behavior of economic agents. The consistency between individual behavior and market dynamics is imposed by a central coordinator from outside the system. In contrast to the tâtonnement process, within our setting boundedly rational agents sequentially adapt their behaviour to market conditions. Market clearing per se does not guarantee that a general equilibrium has been reached as agents might have incentives to update their behaviour despite market clearing. ${ }^{2}$ However, the steady-states of the dynamics are general equilibria (see Proposition 1 in Gualdi and Mandel (2016)). Moreover, these dynamics have strong properties of convergence towards equilibrium. Gualdi and Mandel (2016) numerically show convergence to general equilibrium for all but degenerate values of $\tau_{p}$ and $\tau_{w}$, while (Mandel and Veetil 2019) provides a formal proof of convergence in the limit of small $\theta$. These strong stability properties and the boundedly rational and adaptive nature of the response of agents to economic conditions make the model well-suited to simulate the response of the economy to large unexpected shock, such as the COVID-19 pandemic, and the out-of-equilibrium paths it may follow in reverting back to equilibrium.

\section{Shock Propagation in the Global Economy}

\section{Propagation of Impacts Through Supply Chains}

For a given value of the elasticity parameter $\theta$, we calibrate the parameters $(\mathcal{M}, \alpha, \beta)$ of the model so that the equilibrium input-output flows of the economy correspond to the flows provided in the latest version of the world input-output database (Timmer et al. 2015). Furthermore, we initialize the output, prices, monetary balances, and inventories of all agents to their equilibrium values. In particular, parameters are normalized such that the equilibrium price of every good is 1 . Prior to any simulation, we numerically check that the resulting general equilibrium is a steady-state of the dynamics defined by Eqs. 3 to 9. We then calibrate the direct impact of a COVID-19 lockdown shocks as follows:

- For each country $k \in \mathcal{K}$, we infer from public sources ${ }^{3}$ the $\operatorname{start}\left(T_{s}(k) \in \mathbb{N}\right)$ and end dates $\left(T_{e}(k) \in \mathbb{N}\right)$ of COVID-19 related lockdown measures (see Table 1 in the Appendix). These define two distinct time-periods: the first 40 days, from February the 1st 2020 to March the 15th 2020, correspond to a period where lockdown measures were only ${ }^{4}$ implemented in China. The second period ranges from day 43 to day 100 . Most world countries have implemented lockdown measures in the 10 first days of this period that are lifted after 40 to 60 days..$^{5}$

\footnotetext{
${ }^{2}$ This is even generically the case when prices are perfectly flexible, i.e. $\tau_{p}=1$.

${ }^{3}$ Collated in the entry on "national responses to the 2019-20 coronavirus pandemic" of the online encyclopaedia wikipedia.

${ }^{4}$ With the exception of Italy, which implemented a lockdown on $9^{\text {th }}$ March 2020.

${ }^{5}$ According to expectations at the time of writing.
} 
- For each country $k \in \mathcal{K}$, we assume that during the COVID-19 lockdown measures, the output of firm $i$ and its demand for inputs is bounded below a fixed proportion of the initial equilibrium output. This bound is assumed to represent the direct impairment to production induced by social distancing measures such as closure of production facilities, reduced labor supply, or transport disruptions. The bound is calibrated on the basis of the scenarios provided by the (IFO-Institute 2020), which postulate that sectors related to food, health and public administration operate at $100 \%$ of their capacity, services operate between $50 \%$ and $80 \%$ of capacity, and manufacturing (except food and health related) operates at less than $20 \%$ of capacity (see Table 2 in the Appendix for details). Let $\rho_{j} \in[0,1]$ denote the bound on production of agent $j \in \mathcal{M}$ during the lockdown. We assume (i) that the nominal demand from agent $j$ to agent $i$ is bounded above by $a_{i, j}^{*} \rho_{j} m_{j}^{*}$ and (ii) that the real purchase by agent $j$ of input from agent $i$ is bounded above by $\rho_{j} x_{i, j}^{*}$. This means output is bounded above by $\rho_{j} q_{j}^{*}$ where $a_{i, j}^{*}$, $m_{j}^{*}, x_{i, j}^{*}$ and $q_{j}^{*}$ correspond to initial steady state values.

- Given the very large scale impacts induced by the COVID-19, Equation 4 leads to unreastically large price volatility. To filter out this effect, we mainly report quantitative results in a setting where prices are downwards rigid, i.e. prices are bounded below by their equilibrium values. Results with full price flexibility are reported in Remark 4 below.

Through these direct impacts, COVID lockdown measures impact the production process and propagate therefrom through the economy according to Eqs. 3 to 9. We investigate the magnitude of these impacts for speeds of price adjustment in $\{0.3,0.6,0.9\}$, speeds of technological adjustment in $\{0.3,0.6,0.9\}$, and volatility parameter $\theta \in\{-2,-1,0,0.5,0.75\}$. There are no confidence bounds associated with the results as the model is fully deterministic.

This first round of simulations allow in particular to distinguish the direct impacts of lockdown and its propagation through global supply chains. Results are reported in Figs. 1 and 2. The direct impacts, i.e. the upperbound on potential output implied by the lockdown is independent of the parameters of the model. As manufacturing sectors are the most adversely affected in our scenario, the temporal evolution of direct impacts highlight the
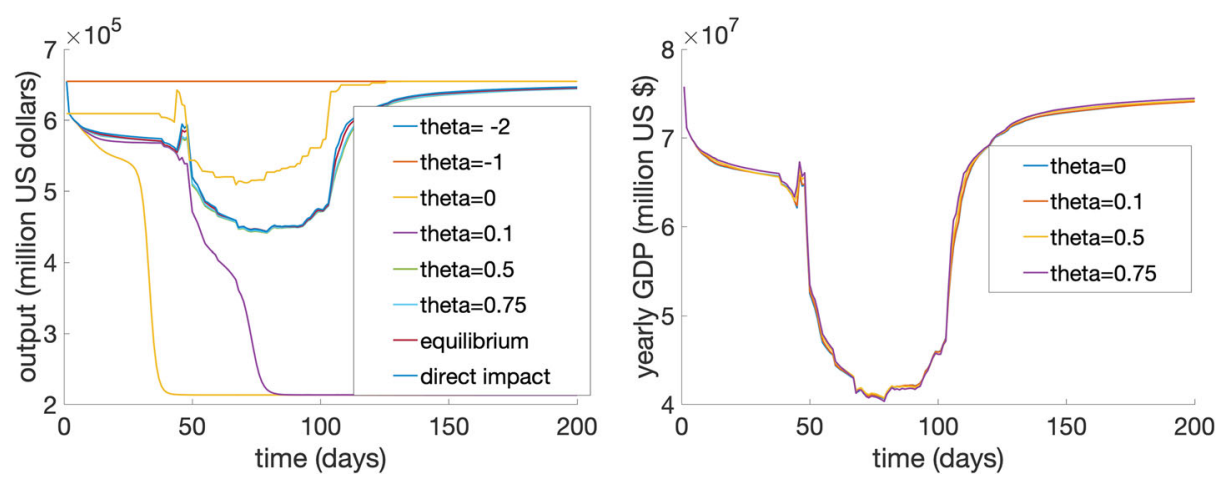

Fig. 1 Dynamics of global output (left panel) and global GDP (right panel) for a range of values of the elasticity parameter $\theta$. For output, are also reported the output given direct impacts and the equilibrium level of output. All values are in million U.S dollars. The Chinese lockdown ends at day 43. In major high-income economies, the lockdown is assumed to end around day 100. Speed parameters for price and technological adjustment, $\tau_{p}$ and $\tau_{w}$, are set to 0.6 

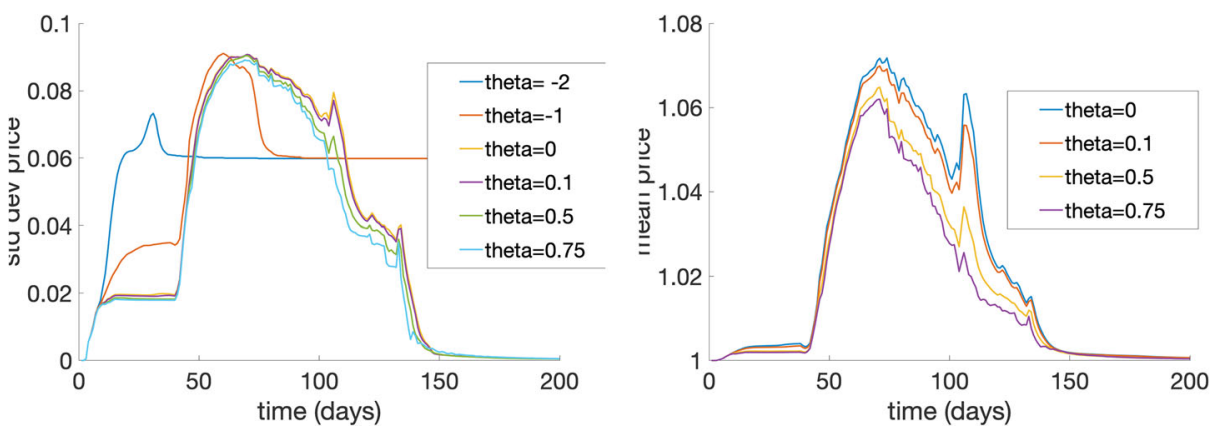

Fig. 2 Dynamics of mean price value (left panel) and standard deviation of prices (right panel) for a range of values of the elasticity parameter $\theta$. All values are in million U.S dollars. The Chinese lockdown ends at day 43. In major high-income economies, the lockdown is assumed to end around day 100. Speed parameters for price and technological adjustment, $\tau_{p}$ and $\tau_{w}$, are set to 0.6

crucial role of China in global manufacturing (see "direct impact" in Fig. 1). Indeed average output falls by $7 \%$ during the first period where China is the only impacted country and by $23 \%$ at the peak of the crisis where almost all countries except China are under lockdown. Indirect supply chain impacts are then determined by the dynamics of the model.

The speed of price and technology adjustments appear to have negligible impact on the dynamics which are mainly driven by quantity constraints. The crucial determinant of supply chain impacts is the elasticity of substitution, or more precisely whether inputs are complements $(\sigma<1)$ or substitutes $(\sigma \geq 1)$. If inputs are strong complements, supply chains are completely disorganised during the lockdown. This leads to a massive amplification-more than two folds-of the direct impact of lockdown through supply chain effects. It is worth pointing out that the bulk of this effect can be generated by China alone. This highlights the role of China in global manufacturing and the massive amplification effects induced by strong complementarities. The disruption of supply chains emerging with strong complementarities are capable of jolting the economy permanently out-of-equilibrium as illustrated in the right panel of Fig. 2. (Note that within our setting the standard deviation of prices can be used as a measure of the distance to equilibrium since the equilibrium value of all prices is one). We believe the impact of the lockdown is unrealistically exacerbated under the complementary of inputs generated by the CES production function. Under these assumptions international inputs can hardly be substituted by domestic ones. Quantitative impacts of inputs are thus likely to be over-estimated. We ease this unrealistic setup by assuming inputs are substitutes, which we use as the reference scenario in the analysis to follow.

Within the regime where inputs are substitutes, the actual value of $\sigma$ has little qualitative or quantitative impact. ${ }^{6}$ The crisis unfolds similarly for a wide range of values of $\sigma$. As highlighted in Figs. 1 and 2, one observes two successive shocks on output corresponding to the Chinese and global lockdown measures. The world economy then reverts back to the initial equilibrium in approximately 50 days following the end of lockdown measures. Supply chain effects amplify direct impact on output by up to $76 \%$ during the period when China is the only country under lockdown. The amplification effects during global lockdown is of

\footnotetext{
${ }^{6}$ It must be noted that for different values of $\sigma$, the parameters $\beta$ of the CES production function are calibrated differently so that the initial equilibria coincide with input-output data.
} 
smaller magnitude reaching a maximal value of $46 \%$. These results highlight the key role of China in global supply chains. Overall, the impact of the lockdowns at the peak of the crisis amount to $33 \%$ of global output while the total impact amounts to $9.4 \%$ of annual GDP. Figure 3 highlights geographical distribution of impacts (see also Table 3 in the Appendix). The magnitude of impacts depend on the duration of the lockdown in the country and of its dependance on international trade.

Remark 4 Indirect impacts are partly mitigated if prices are fully flexible. In this setting, the amplification of direct impact on output is at most $32 \%$ during the Chinese lockdown and 35\% during the global lockdown. The impact at the peak of the crisis amounts to $31 \%$ of global output, while the total impact amounts to $7.3 \%$ of annual GDP.

\section{Behavioral Propagation Of Impacts}

Beyond disruptions of global supply chains, a major shock on economic activity and incomes such as the one induced by the COVID lockdowns might have long-lasting impact on the confidence of economic actors and thus on final demand. Such a confidence shock is of particular relevance following a completely unexpected event such as the COVID 19 epidemic (see Goeschl and Managi (2019), for a related discussion on the role of expectations in disaster preparedness). In order to assess the potential magnitude of such effects, we introduce a form of hysteresis in final demand. More precisely, we consider that households use a form of "maxmin" strategy to determine their level of spending, which they fix according to the minimal income received in the $T_{0}$ last periods. That is for all $h \in \mathcal{H}$, demand is determined by substituting $\min _{\left.s \in\left(t-T_{0}, t\right]\right)} \sum_{j \in \mathcal{F}} a_{h, j} m_{j}^{s}$ to $m_{h}^{t}$. Note that at equilibrium

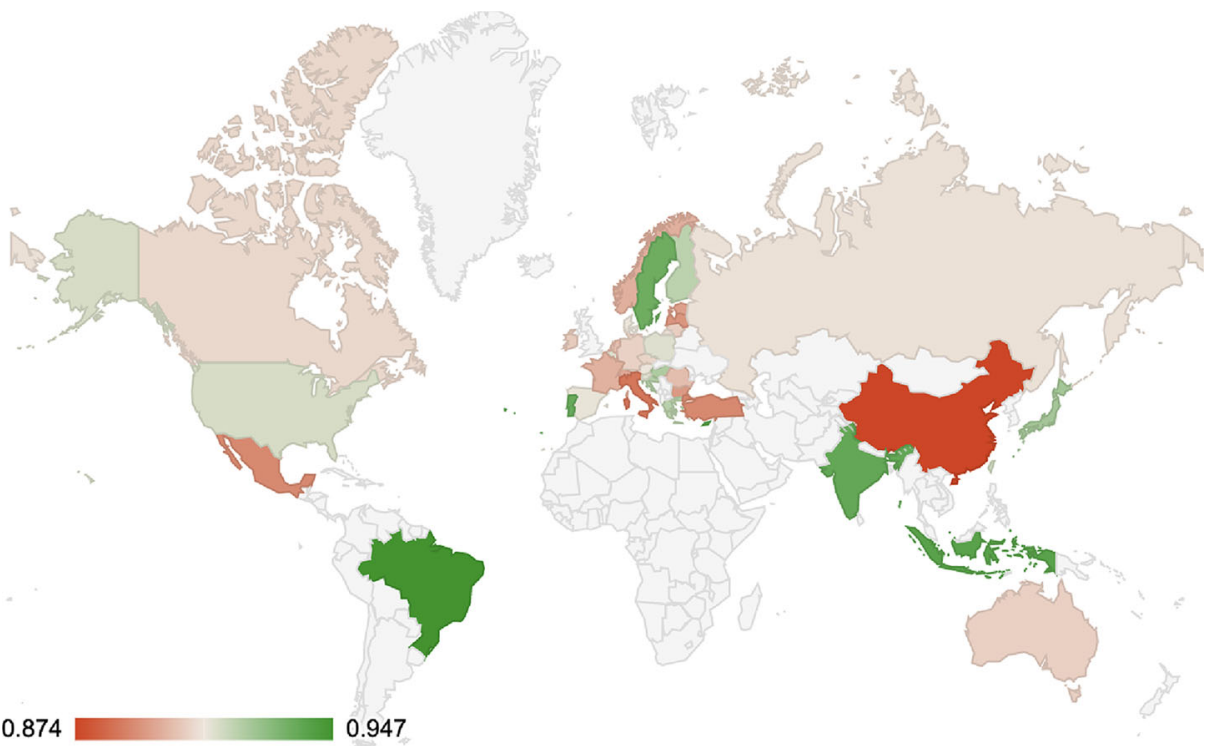

Fig. 3 Heatmap representing the ratio between annual GDP in the covid scenario and at steady-state for countries in the wiod dataset 

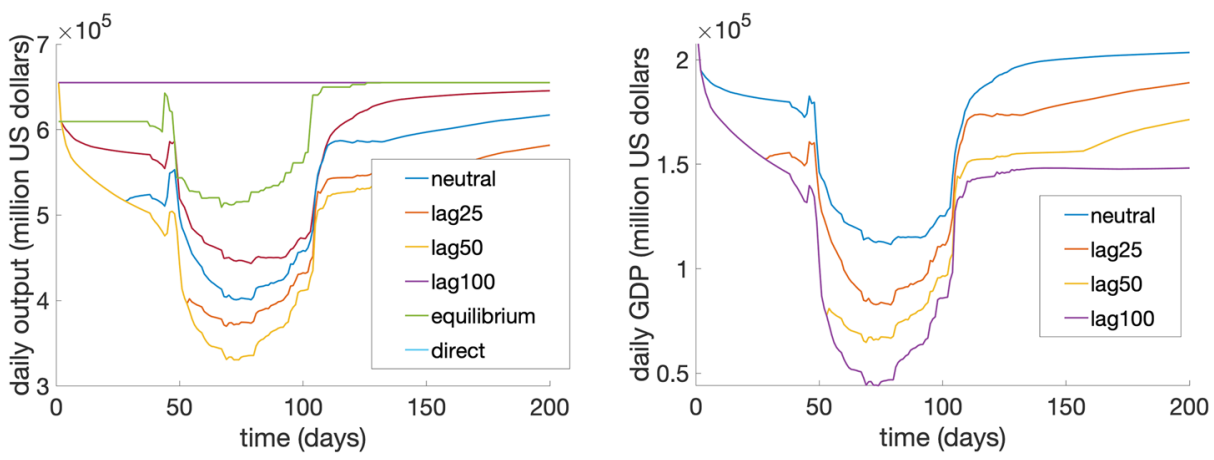

Fig. 4 Dynamics of global output (left panel) and global GDP (right panel) for the reference scenario (neutral) and a range of values of the lag parameter $T_{0}$ for household spending in the scenario with confidence shock. For output, are also reported the output given direct impacts and the equilibrium level of output. All values are in million U.S dollars. The Chinese lockdown ends at day 43. In major high-income economies, the lockdown is assumed to end around day 100. Elasticity parameter is set to $\theta=0.5$. Speed parameters for price and technological adjustment, $\tau_{p}$ and $\tau_{w}$, are set to 0.6

$m_{h}^{*}=\sum_{j \in \mathcal{F}} a_{h, j} m_{j}^{*}$ so that this alternative assumption does not modify the steady states of the model.

As highlighted in Fig. 4, such a confidence shock has a major impact on the dynamics. The magnitude of impacts is exacerbated and the recovery of the economy delayed. The magnitude of the confidence induced effect can be commensurate with the original effect. Assuming a 50 days lag $\left(T_{0}=50\right)$, the impact on output at the peak of the crisis reaches $44 \%$ of equilibrium output and the total annual impact on GDP amounts to $19 \%$ of equilibrium GDP.

We finally investigate the impact of policy measures aiming at mitigating this confidence shock by guaranteeing the income of households throughout the crisis (at their equilibrium value) through public subsidies. Such measures are akin to the short-time work measured implemented in a number of European countries. As highlighted in Fig. 5, they are efficient in mitigating the confidence shock. They even allow to improve upon the reference scenario by supporting final demand during the crisis. These results thus hint at the short-term efficiency of such policy measures. However, potential negative long-term impacts due to increased public debt are not accounted for in the model.

\section{Concluding Remarks}

In this paper, we have used an agent-based model of out-of-equilibrium economic dynamics to estimate the cost of the COVID-19 lockdowns. We use the major simplifying assumption that lockdown mesures are implemented in an uniform manner and that there is no direct impact in countries that have not implemented an explicit lockdown (e.g. Korea and Sweden). Conditional on data availability, a country-specific modelling of lockdowns measures can be implemented. However, readily exploitable data from this perspective is likely to be available only à posteriori.

At present our model is calibrated on the Word Input Output Tables (Timmer et al. 2015) and relies on estimates of the dynamics of the COVID-19 pandemic and of the associated policy response that were published in early May 2020 (IFO-Institute 2020). Our model 

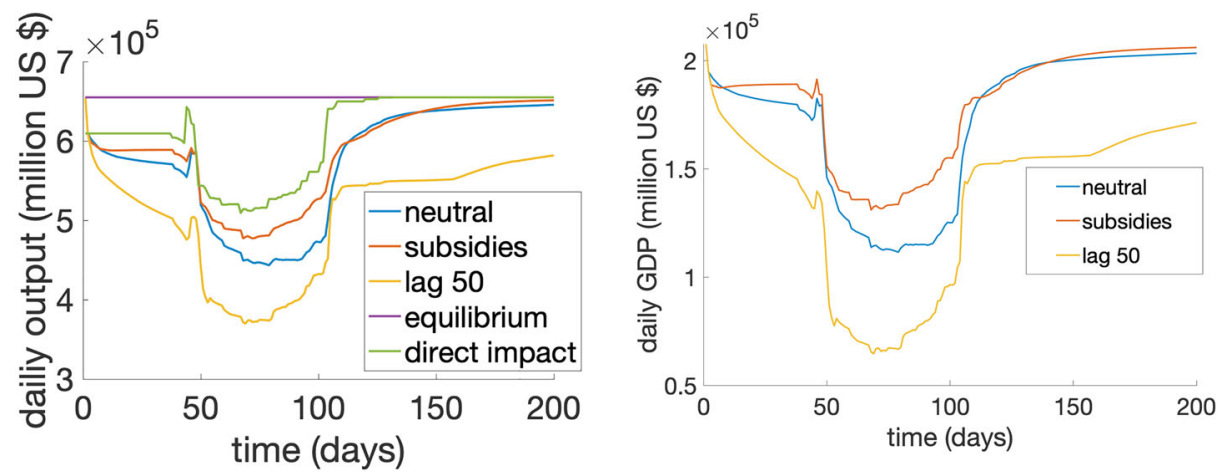

Fig. 5 Dynamics of global output (left panel) and global GDP (right panel) for the reference scenario (neutral), the scenario with a confidence shock at lag 50 without and with public subsidies (label subsid). For output, are also reported the output given direct impacts and the equilibrium level of output. All values are in million U.S dollars. The Chinese lockdown ends at day 43. In major high-income economies, the lockdown is assumed to end around day 100. Elasticity parameter is set to $\theta=0.5$. Speed parameters for price and technological adjustment, $\tau_{p}$ and $\tau_{w}$, are set to 0.6

accounts both for direct impacts of the lockdowns and its propagation through the global supply chain. Our estimate of the total impact amounts to $9 \%$ of global GDP. This estimate is in line with the upper range of estimates published by international organisations (see Table 4 in the Appendix). These upper hand estimates, as opposed to the lower hand ones, are themselves obtained through models that account for indirect or supply chain effects (see e.g. Kohlscheen et al. (2020)). Our estimates rely on the assumption, prevailing at the date of writing, that lockdown measures will be lifted after 50 days in average. The dynamics of the model suggest that the costs would increase linearly with the duration of the lockdown if it were to be extended. This assumption is also consistent with concurrent estimates reported in the Appendix, some of which are expressed in terms of cost per week/month of lockdown. Our simulations also show that the cost increases substantially if the recovery is hampered by a major confidence shock.

We are still in the early days of the analysis of economic costs of lockdowns implemented by many governments in the wake of the pandemic. Nonetheless, what has become evident is that multiple models are needed to address different questions. Models which shed light on longterm consequences will have to be somewhat different from those which explain short and medium term dynamics, at least in part because economic agents are likely to adapt to new circumstances. These new circumstances include the policy risk faced by firms who source inputs from suppliers situated within geographical regions administered by governments different from their own. In similar vain, models intended to study the impact of monetary policy responses may have to explicitly consider indebtedness and liquidity constraints.

Supply-chain dynamics however are likely to be an important ingredient of many models. In this paper, we have illustrated how one such supply-chain system can be calibrated to the world economy and how the calibrated system can be used to study disequilibrium dynamics that follow from an exogenous shock. Ours is however primarily an analysis of the short and medium run. One of the assumptions which limits our model's ability to say much about the long-run is the assumption that agents cannot change their input providers, though they can change the proportions in which they combine inputs. In the longer run, the COVID virus, its policy responses, and the risk of similar policy responses in the future is likely to generate a 
remarkable reorganization of the global supply chain. Firms may diversify among suppliers of inputs and source inputs from within national or regional areas. The model presented in this paper can be extended to study the longrun reorganization of the world supply chain network. In fact, such a version of the model is used by Gualdi and Mandel (2018) to study the emergence of endogenous growth when firms change input sellers in response to technological improvements. Our model can also be coupled with epidemiological models of the spread of the virus and labor market models wherein labor dynamics too percolate from one market to another.

\section{Appendix}

Table 1 Lockdown start and end dates by countries according to public sources collated from the entry on "national responses to the 2019-20 coronavirus pandemic" of the online encyclopaedia wikipedia on April 20th 2020

\begin{tabular}{|c|c|c|}
\hline Country & Lockdown start date & Lockdown end date \\
\hline Australia & 51 & 106 \\
\hline Austria & 44 & 72 \\
\hline Belgium & 46 & 78 \\
\hline Bulgaria & 76 & 131 \\
\hline Brazil & 45 & 67 \\
\hline Canada & 45 & 100 \\
\hline Switzerland & 45 & 100 \\
\hline China & 0 & 43 \\
\hline Cyprus & 52 & 72 \\
\hline Czech Republik & 44 & 71 \\
\hline Germany & 48 & 78 \\
\hline Denmark & 39 & 72 \\
\hline Spain & 42 & 84 \\
\hline Estonia & 41 & 90 \\
\hline Finland & 55 & 75 \\
\hline France & 45 & 100 \\
\hline Uk & 52 & 107 \\
\hline Greece & 51 & 86 \\
\hline Croatia & 46 & 78 \\
\hline Hungary & 56 & 69 \\
\hline Indonesia & 69 & 82 \\
\hline India & 53 & 92 \\
\hline Ireland & 40 & 94 \\
\hline Italy & 37 & 92 \\
\hline Japan & 66 & 95 \\
\hline Korea & 0 & 0 \\
\hline Lithuania & 44 & 86 \\
\hline Luxembourg & 46 & 101 \\
\hline Latvia & 76 & 131 \\
\hline Mexico & 58 & 119 \\
\hline Malta & 40 & 95 \\
\hline Netherlands & 44 & 87 \\
\hline Norway & 40 & 72 \\
\hline
\end{tabular}


Table 1 (continued)

\begin{tabular}{lll}
\hline Country & Lockdown start date & Lockdown end date \\
\hline Poland & 41 & 70 \\
Portugal & 47 & 61 \\
Romania & 53 & 101 \\
Russia & 58 & 90 \\
Slovak & 44 & 99 \\
Slovenia & 43 & 76 \\
Sweden & 0 & 0 \\
Turkey & 70 & 125 \\
Taiwan & 0 & 0 \\
USa & 47 & 102 \\
Rest of the World & 48 & 103 \\
\hline
\end{tabular}

Table 2 Ratio between production under lockdown and default/equilibrium production levels according to the IFO low impact scenario (IFO-Institute 2020)

Crop and animal production, hunting

and related service activities

Forestry and logging 1

Fishing and aquaculture 1

Mining and quarrying

Manufacture of food products, beverages and tobacco products 1

Manufacture of textiles, wearing apparel and leather products

Manufacture of wood and of products of wood

Manufacture of paper and paper products

Printing and reproduction of recorded media

Manufacture of coke and refined petroleum products

Manufacture of chemicals and chemical products

Manufacture of basic pharmaceutical products

Manufacture of rubber and plastic products

Manufacture of other non-metallic mineral products

Manufacture of basic metals

Manufacture of fabricated metal products

Manufacture of computer, electronic and optical products

Manufacture of electrical equipment

Manufacture of machinery and equipment n.e.c.

Manufacture of motor vehicles, trailers and semi-trailers $\quad 0.2$

Manufacture of other transport equipment $\quad 0.2$

$\begin{array}{lc}\text { Manufacture of furniture; other manufacturing } & 0.2\end{array}$

Repair and installation of machinery and equipment $\quad 0.2$

Electricity, gas, steam and air conditioning supply 1

Water collection, treatment and supply 1

Sewerage; waste collection, treatment and disposal activities; $\quad 1$ 
Table 2 (continued)

Sector

Lockdown production ratio

Construction

Wholesale and retail trade and repair of motor vehicles and motorcycles

Wholesale trade, except of motor vehicles and motorcycles

Retail trade, except of motor vehicles and motorcycles

Land transport and transport via pipelines

Water transport

Air transport

Warehousing and support activities for transportation

Postal and courier activities

$\begin{array}{ll}\text { Accommodation and food service activities } & 0.2\end{array}$

$\begin{array}{ll}\text { Publishing activities } & 0.8\end{array}$

Motion picture, video and television programme productions 0.8

$\begin{array}{ll}\text { Telecommunications } & 0.8\end{array}$

$\begin{array}{ll}\text { Computer programming, consultancy and related } & 0.8\end{array}$

activities; information service activities

Financial service activities, except insurance and pension funding 0.5

Insurance, reinsurance and pension funding, except compulsory 0.5

social security

Activities auxiliary to financial services and insurance activities 0.5

$\begin{array}{ll}\text { Real estate activities } & 0.5\end{array}$

Legal and accounting activities; $\quad 0.8$

Architectural and engineering activities; $\quad 0.5$

$\begin{array}{ll}\text { Scientific research and development } & 0.5\end{array}$

$\begin{array}{ll}\text { Advertising and market research } & 0.5\end{array}$

Other professional, scientific and technical activities; 0.8

$\begin{array}{ll}\text { Administrative and support service activities } & 0.2\end{array}$

Public administration and defence; compulsory social security 1

Education 1

Human health and social work activities 1

$\begin{array}{ll}\text { Other service activities } & 0.2\end{array}$

Activities of households as employers; $\quad 0.5$

Activities of extraterritorial organizations and bodies $\quad 0.5$

Table 3 The table provides (i) the value of GDP 2014 in million dollars from world input-output database used as equilibrium value of GDP and (ii) the ratio between annual GDP under the reference shock scenario and equilibrium GDP per country

\begin{tabular}{lll}
\hline Country & Equilibrium GDP (Mil. US\$) & GDP Shock Ratio \\
\hline Australia & 1391249 & 0.906 \\
Austria & 405532 & 0.911 \\
Belgiuc & 503658 & 0.914 \\
Bulgaria & 52810 & 0.894 \\
Brazil & 2266351 & 0.946 \\
Canada & 1720495 & 0.907
\end{tabular}


Table 3 (continued)

\begin{tabular}{|c|c|c|}
\hline Country & Equilibrium GDP (Mil. US\$) & GDP Shock Ratio \\
\hline Switzerland & 702082 & 0.897 \\
\hline China & 10400634 & 0.874 \\
\hline Cyprus & 23282 & 0.940 \\
\hline Czech Republic & 199046 & 0.907 \\
\hline Germany & 3686682 & 0.906 \\
\hline Denmark & 318749 & 0.911 \\
\hline Spain & 1304842 & 0.911 \\
\hline Estonia & 24959 & 0.895 \\
\hline Finland & 248398 & 0.92 \\
\hline France & 2651679 & 0.899 \\
\hline Uk & 2810857 & 0.906 \\
\hline Greece & 223022 & 0.92 \\
\hline Croatia & 51712 & 0.921 \\
\hline Hungary & 126943 & 0.922 \\
\hline Indonesia & 880112 & 0.94 \\
\hline India & 2108269 & 0.937 \\
\hline Ireland & 242217 & 0.905 \\
\hline Italy & 2008835 & 0.886 \\
\hline Japan & 4511548 & 0.924 \\
\hline Korea & 1371790 & 0.93 \\
\hline Lithuania & 49879 & 0.905 \\
\hline Luxembourg & 61249 & 0.9 \\
\hline Latvia & 29517 & 0.893 \\
\hline Mexico & 1247401 & 0.89 \\
\hline Malta & 10220 & 0.89 \\
\hline Netherlands & 831228 & 0.902 \\
\hline Norway & 487441 & 0.899 \\
\hline Poland & 512961 & 0.913 \\
\hline Portugal & 216127 & 0.936 \\
\hline Romania & 187007 & 0.902 \\
\hline Russia & 1724371 & 0.909 \\
\hline Slovak & 100298 & 0.884 \\
\hline Slovenia & 49125 & 0.913 \\
\hline Sweden & 534672 & 0.935 \\
\hline Turkey & 754440 & 0.89 \\
\hline Taiwan & 535506 & 0.916 \\
\hline USA & 17490037 & 0.915 \\
\hline Rest of the World & 10730881 & 0.898 \\
\hline
\end{tabular}


Table 4 Impacts on global GDP forecasted by major international organisations

\begin{tabular}{llll}
\hline Source & Impact on annual world GDP in \% & Date & Reference \\
\hline World Bank & -2 to -4 & April 10th 2020 & (Maliszewska et al. 2020) \\
WTO & -4.8 to -8.11 & April 8th 2020 & (WTO 2020) \\
BIS & -2.5 to -5 direct , -5 & April 6th 2020 & (Kohlscheen et al. 2020) \\
& to -10 total & & \\
IMF & -6 & April 14th 2020 & (IMF 2020) \\
OECD & -20 to -25 per month of & April 8th 2020 & (WTO 2020) \\
& lockdown & & \\
Asian Development & -6.4 to -9.7 & May 15th 2020 & (Park et al. 2020) \\
Bank & & & \\
\hline
\end{tabular}

\section{References}

Acemoglu D, Carvalho VM, Ozdaglar A, Tahbaz-Salehi A (2012) The network origins of aggregate fluctuations. Econometrica 80(5):1977-2016

Alfaro L, Chari A, Greenland AN, Schott PK (2020) Aggregate and firm-level stock returns during pandemics, in real time. NBER Working Paper No. 26950

Arrow KJ, Hurwicz L (1958) On the stability of the competitive equilibrium. Econometrica: Journal of the Econometric Society 522-552

Asian Development Bank (2020) The economic impact of the COVID-19 outbreak on developing Asia. ADB Briefs 128:1-14

Baker SR, Bloom N, Davis SJ, Terry SJ (2020) The unprecedented stock market reaction to covid-19. NBER Working Paper No. 26983

Barro RJ, Grossman H (1971) A general disequilibrium model of income and employment. Am Econ Rev 61(1):82-93

Barro RJ, Ursua JF, Weng J (2020) The Coronovirus and the great influenza pandemic: Lessons from the 'Spanish Flu' for the Coronavirus's potential effects on mortality and economic activity. CESifo Working Paper No. 8166

Barrot JN, Grassi B, Sauvagnat J (2020) Sectoral effects of social distancing. COVID Econ 3:85-102

Barrot JN, Sauvagnat J (2016) Input specificity and the propagation of idiosyncratic shocks in production networks. Quart J Econ 131(3):1543-1592

Battiston S, Gatti DD, Gallegati M, Greenwald B, Stiglitz JE (2007) Credit chains and bankruptcy propagation in production networks. J Econ Dyn Control 31(6):2061-2084

Bayer C, Born B, Luetticke R, Muller GJ (2020) The coronavirus stimulus package: How large is the transfer multiplier? Working Paper, 9 April

Benassy J-P (1975) Neo-Keynesian disequilibrium theory in a monetary economy. Rev Econ Stud 42(4):503523

Bernstein J, Richter AW, Throckmorton NA (2020) COVID-19: A view from the labor market. Federal Reserve Bank of Dallas Working Paper

Bodenstein M, Corsetti G, Guerrieri L (2020) Social distancing and supply chain disruptions in a pandemic. Finance and Economics Discussion Series Divisions of Research and Statistics and Monetary Affairs Federal Reserve Board, Washington, D.C., 31

Boehm CE, Flaaen A, Pandalai-Nayar N (2019) Input linkages and the transmission of shocks: Firm-level evidence from 2011 Tohoku earthquake. Rev Econ Stat 101(1):60-75

Boschen J, Grossman HI (1982) Tests of equilibrium macroeconomics using contemporaneous monetary data. J Monet Econ 10:309-333

Carvalho VM, Nirei M, Saito Y (2014) Supply chain disruptions: Evidence from the great east Japan earthquake Discussion Papers 14035. Research Institute of Economy, Trade and Industry (RIETI) 
Chatterjee P (2020) Indian pharma threatened by COVID-19 shutdowns in China. The Lancet World Report, 395

Dawid H, Harting P, Neugart M (2014) Economic convergence: Policy implications from a heterogeneous agent model. J Econ Dyn Control 44:54-80

del Rio-Chanona RM, Mealy P, Pichler A, Lafond F, Farmer JD (2020) Supply and demand shocks in the COVID-19 pandemic: An industry and occupation perspective

Dosi G, Fagiolo G, Napoletano M, Roventini A (2013) Income distribution, credit and fiscal policies in an agent-based keynesian model. J Econ Dyn Control 37(8):1598-1625

Fair RC, Jaffee DM (1972) Methods of estimation for markets in disequilibrium. Econometrica 40(3):454497

Fornaro L, Wolf M (2020) COVID-19 coronavirus and macroeconomic policy. Working Paper, 21 March

Gatti DD, Di Guilmi C, Gaffeo E, Giulioni G, Gallegati M, Palestrini A (2005) A new approach to business fluctuations: Heterogeneous interacting agents, scaling laws and financial fragility. J Econ Behav Organ 56(4):489-512

Goeschl T, Managi S (2019) Public in-kind relief and private self-insurance. Economics of Disasters and Climate Change 3(1):3-21

Gormsen NJ, Koijen RSJ (2020) Coronavirus: Impact on stock prices and growth expectations. Working Paper, 22 April

Gourieroux C, Monfort JJL (1980) A Disequilibrium econometrics in simultaneous equation systems. Econometrica 68(1):75-96

Green J, Laffont J-J (1980) Disequilibrium dynamics with inventory and anticipatory price-setting. NBER Working Paper No. 453

Gualdi S, Mandel A (2016) On the emergence of scale-free production networks. J Econ Dyn Control 73:6177

Gualdi S, Mandel A (2018) Endogenous growth in production networks. J Evol Econ 29(1):1-27

Hallegatte S (2008) An adaptive region input-output model and its application to the assessment of the economic cost of Katrina. Risk Anal 28(3):779-799

Hassan TA, van Lent L, Hollander S, Tahoun A (2020) Firm-level exposure to epidemic diseases: COVID-19, SARS, and H1N1. Working Paper, 1 April

IFO-Institute (2020) The economic costs of the coronavirus shutdown for selected european countries: A scenario calculation

IMF (2020) World economic outlook april 2020: The great lockdown. International Monetary Fund, Technical report

Inoue H, Todo Y (2020) The propagation of the economic impact through supply chains: The case of a mega-city lockdown against the spread of covid-19. Working Paper

Ito T (1980) Methods of estimation for multi-market disequilibrium models. Econometrica 48(1):97-125

Jorgenson DW (1961) Stability of a dynamic input-output system. Rev Econ Stud 28(2):105-116

Kohlscheen E, Mojon B, Rees D (2020) The macroeconomic spillover effects of the pandemic on the global economy, Available at SSRN 3569554

Lamperti F, Bosetti V, Roventini A, Tavoni M (2019) The public costs of climate-induced financial instability. Nat Clim Change 9(11):829-833

Leontief WW (1941) The structure of the American economy. Oxford University Press, Oxford

Maliszewska M, Mattoo A, Van Der Mensbrugghe D (2020) The potential impact of covid-19 on gdp and trade: A preliminary assessment

Mandel A, Veetil V (2019) Monetary dynamics in a network economy. University of Paris 1 Working Paper, HAL ID halshs-02354576

Muellbauer J, Portes R (1978) Macroeconomic models with quantity rationing. Econ J 88(352):788-821

Park C-Y, Villafuerte J, Abiad A (2020) Updated assessment of the potential economic impact of covid-19

Quandt RE (1978) Tests of the equilibrium versus disequilibrium hypotheses. Int Econ Rev 19(2):435-452

Riddel M (2004) Housing-market disequilibrium: An examination of housing-market price and stock dynamics. J Hous Econ 13(2):120-135

Rosen HS, Quandt RE (1978) Estimation of a disequilibrium aggregate labor market. Rev Econ Stat 60(3):371-379

Rosen S, Nadiri MI (1974) A disequilibrium model of demand for factors of production. Am Econ Rev 64(2):264-270

Rudebusch GD (1989) An empirical disequilibrium model of labor, consumption, and investment. Int Econ Rev 30(3):633-654

Seiichi K, McMillan J, Zimmermann KF (1982) Disequilibrium dynamics: An empirical study. Am Econ Rev 72(5):992-1004

Sharp JK, Perkins WR (1977) A new approach to dynamic input-output models. Automatica 14:77-79 
Takatoshi I, Ueda K (1981) Tests of the equilibrium hypothesis in disequilibrium econometrics. Int Econ Rev 22(3):691-708

Timmer MP, Dietzenbacher E, Los B, Stehrer R, De Vries GJ (2015) An illustrated user guide to the world input-output database: The case of global automotive production. Rev Int Econ 23(3):575-605

Toda AA (2020) Susceptible-infected-recovered (SIR) dynamics of COVID-19 and economic impact. Working Paper

Walmsley T, Rose A, Wei D (2020) Impact of the us macroeconomy of mandatory business closures in response to the COVID-19 pandemic. Working Paper, 6 April

Weisbuch G, Battiston S (2007) From production networks to geographical economics. J Econ Behav Org 64(3-4):448-469

World Bank (2020) Assessing the economic impact of covid-19 and policy responses in Sub-Saharan Africa. The World Bank Africa's Pulse 21:1-123

WTO (2020) Trade set to plunge as covid-19 pandemic upends global economy. World Trade Organization, Technical report

Zeiger D (2020) Supply management's role in curtailing the coronavirus impact: The pandemic has impacted already-strained global supply chains, demand strategic responses from executives and procurement professionals. Institute for Supply Management White Paper

Publisher's Note Springer Nature remains neutral with regard to jurisdictional claims in published maps and institutional affiliations. 